\title{
HYPERTENSION IN A PATIENT WITH SPINAL CORD TRAUMA... CAN CLEVIDIPINE BE AN OPTION?
}
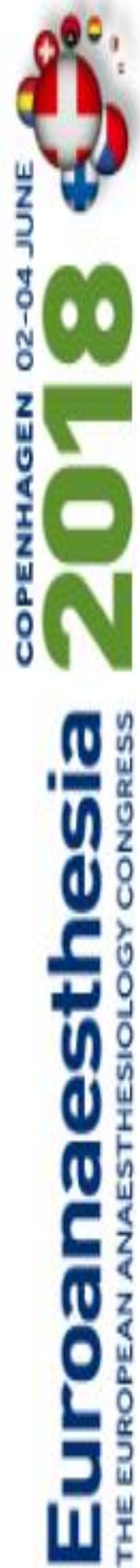

R. Navarro Suay ${ }^{1}$, MA. García-Aroca ${ }^{2}$, E. Pelet-Pascual ${ }^{2}$, E. López Soberón ${ }^{3}$, R. García Cañas ${ }^{4}$, FJ. Areta-Jiménez ${ }^{5}$

${ }^{1}$ Hospital Central de la Defensa Gómez Ulla / IMIDEF, Dept of Anaesthesiology \& Intensive Care, Madrid, Spain

${ }^{2}$ Hospital Central de la Defensa Gómez Ulla / Dept of Anaesthesiology \& Intensive Care, Madrid, Spain

${ }^{3}$ Hospital Central de la Defensa Gómez Ulla / Dept of Cardiology, Madrid, Spain

${ }^{4}$ Hospital Central de la Defensa Gómez Ulla / IMIDEF, Dept of Orthopaedic Surgery and Trauma, Madrid, Spain

${ }^{5}$ Hospital Central de la Defensa Gómez Ulla / Dept of Orthopaedic Surgery and Trauma, Madrid, Spain

\section{BACKGROUND}

Clevidipine is an arterially selective dihydropyridine calcium channel blocker with a half-life of approximately 1 minute. It demonstrates rapid onset and offset of blood pressure-decreasing effect, allowing for responsive titration and a decreased risk of overshoot hypotension. Additionally, because clevidipine undergoes metabolism by ubiquitous plasma esterases, its elimination is independent of the liver and kidney, providing an increased margin of safety in the Emergency Department. Finally, this metabolic degradation pathway may provide a lower potential for drug-drug interactions and is attractive for use when patient characterization is not always well determined before therapy is begun. Several studies support the idea that certain changes in the cerebral circulation are related to the position of first cervical vertebra (C1). On the one hand, superior cervical subluxations (C1-C2) can generate changes in the cerebral circulation (ischemic or compressive), which may be associated with high blood pressure levels. On the other hand, the afferent sensory signals of the suboccipital musculature, through postural reflexes and/or vertebral nerve plexuses, may also have relationship on central cardiorespiratory control and, therefore, also influence it.

\section{CASE REPORT}

Male, 39 years old, who suffer cervical fracture (C5-C6) with spinal cord injury while jumping head in the pool. When arrive to hospital presents: GCS 15 points, arms and legs areflexia, ASIA A, $\mathrm{SaO}_{2}: 95 \%$, BP: 120/50 $\mathrm{mmHg}, \mathrm{HR}: 80 \mathrm{bpm}$. Under general anesthesia, trauma surgeons perform surgical decompression and fixation of two vertebral bodies. During this process, patient suffer hypertension $(140 / 85 \mathrm{mmHg})$ during 6 min in spite of adequate remifentanil dose ( $25 \mathrm{microgr} / \mathrm{Kg} / \mathrm{min}$ ) and it decided employ clevidipine $(2 \mathrm{mg} / \mathrm{h})$ for two hours reaching an adequate blood pressure (approx 125/70 mmHg).

\section{DISCUSSION}

In the paper review carried out, we found that high blood pressure is a complex disease that affects a large percentage of the current population. On the other hand it was found that high cervical trauma can influence in the mechanism that regulate the responses of high blood pressure control system, in some patients. The tight control of mean arterial pressure is mandatory during perioperative time. Several pharmacologic agents have been employed to avoid these abrupt changes in mean arterial pressure including nitroprusside, nitroglycerin, nicardipine, hydralazine or labetalol. Clevidipine is a recently introduced and it can be an alternative in this kind of patient.

\section{REFERENCES}

Eckert M. Martin ML. Surg Clin N Am 97 (2017) 1031-1045.

Zuleta-Alarcón A, Castellón-Larios K, Bergese S. The role of clevedipine in hypertension management: Clinical results. Rev Esp Anestesiol Reanim 2014:61(10):557-564.

Pollack CV, Varon J, Garrison NA, Ebrahimi R, Dunbar L, Peacock WF. Clevidipine, an intravenous dihydropyridine calcium channel blocker, is safe and effective for the treatment of patients with acute severe Hypertension. Annals of Emergency Medicine 2009; 53(3):329-338.

\section{LEARNING POINTS:}

Clevidipine can be an option to blood pressure control in cervical trauma.
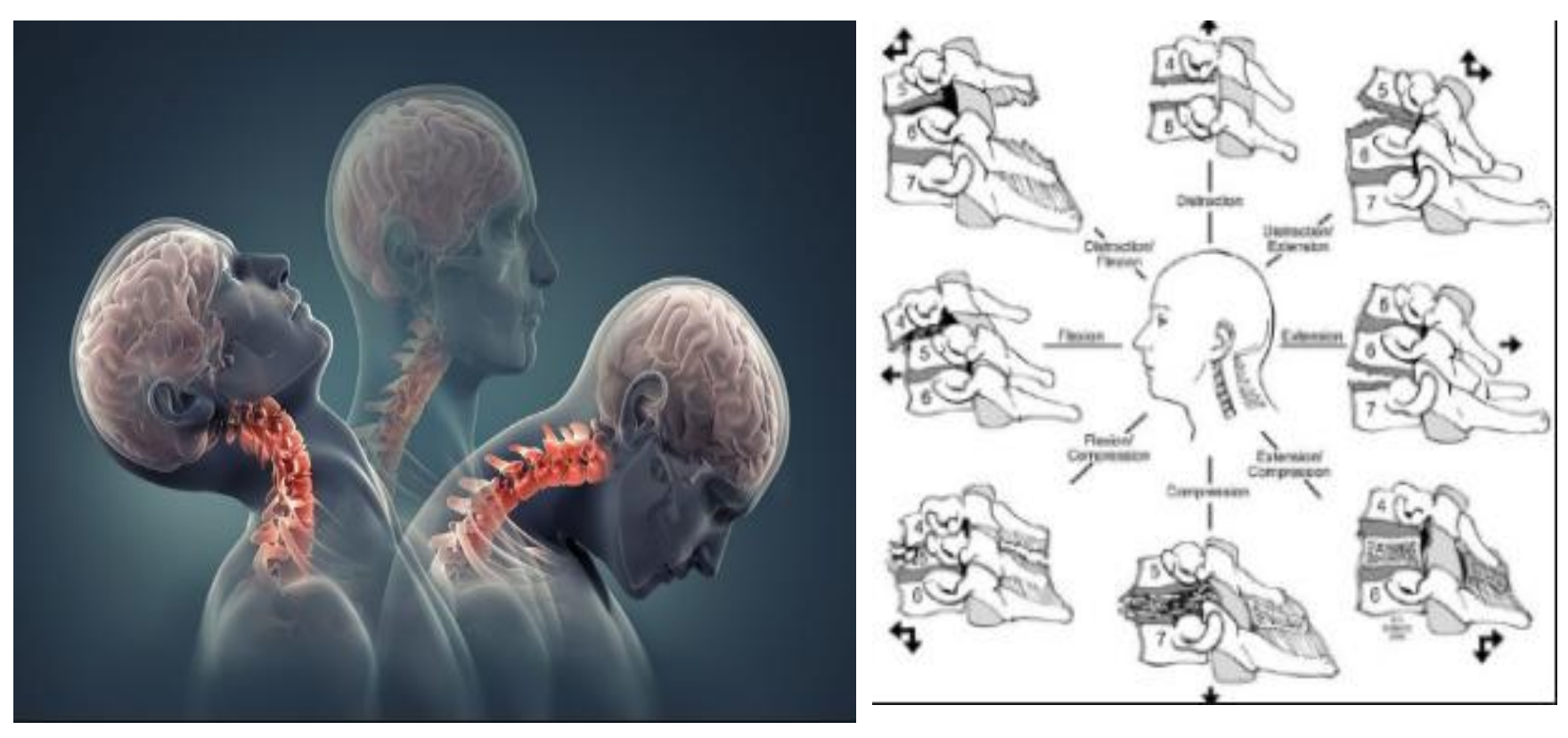
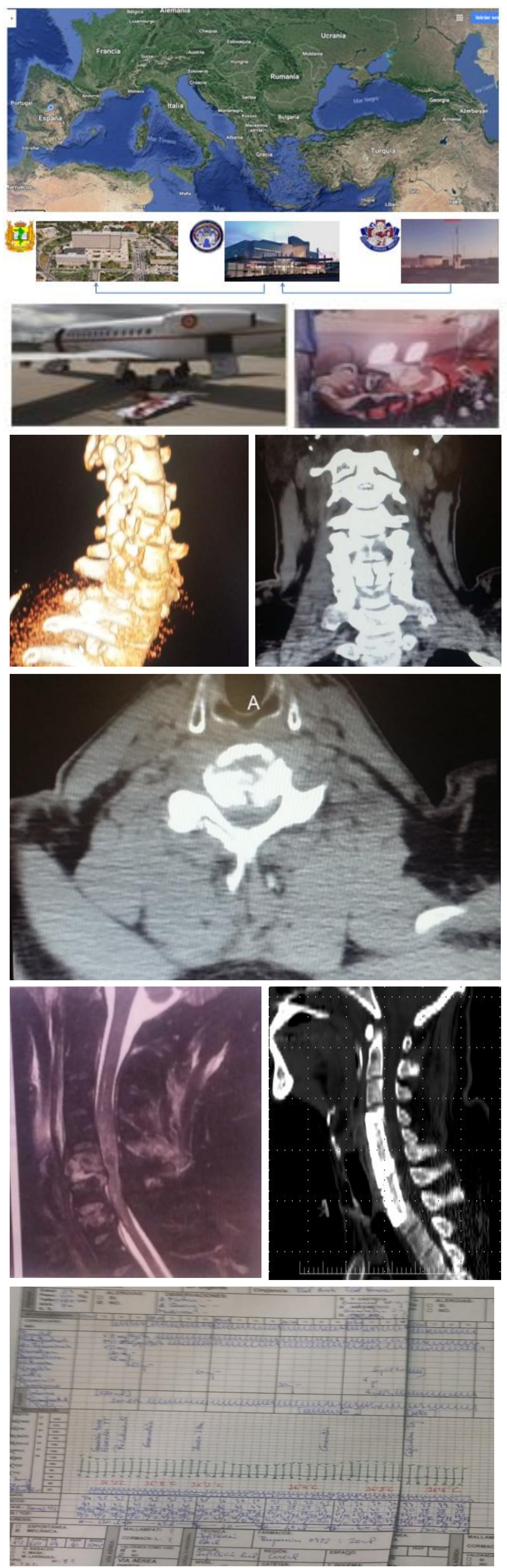